\title{
TRATAMENTO DE EMULSÕES ÓLEO/ÁGUA UTILIZANDO ARGILA VERMICULITA EXPANDIDA ORGANOFÍLICA E HIDROFOBIZADA
}

\author{
V. C. SILVA ${ }^{1}$, J. S. ALBUQUERQUE ${ }^{1}$, B. V. SOUSA ${ }^{1}$ \\ ${ }^{1}$ Universidade Federal de Campina Grande, Departamento de Engenharia Química \\ E-mail: valdetecampossilva@ hotmail.com, jonassantana25@gmail.com, \\ bianca@deq.ufcg.edu.br
}

\begin{abstract}
RESUMO - A minimização dos impactos ambientais causados pelos diversos processos industriais vem se tornando uma preocupação constante na atualidade. A busca por materiais de baixos custos, alta capacidade de remoção de óleo e fácil disponibilidade são fatores importantes para a sua escolha. A argila vermiculita possui uma maior capacidade de adsorção de compostos apolares após um processo de expansão e hidrofobização. Esse trabalho tem como objetivo o tratamento de emulsões óleo/água utilizando a vermiculita expandida organofílica e hidrofobizada, avaliando capacidade de remoção de óleo em emulsões sintéticas. Nos difratogramas observou-se o aumento do espaçamento interlamelar da vermiculita, confirmando a organofilização e a hidrofobização. Através das micrografias observou-se a presença dos materiais orgânicos nas camadas interlamelares e na superfície do material. Ambas as vermiculitas tiveram boas capacidades de remoção e possuem potencial como adsorventes.
\end{abstract}

\section{INTRODUÇÃO}

Os argilominerais são pertencentes à família dos filossilicatos (do grego: phyllon= folha), que podem ser definidos como silicatos, contendo folhas tetraédricas bidimensionais contínuas de composição $\mathrm{Si}_{2} \mathrm{O}_{5}$. Cerca de $80 \%$ dos cátions trocáveis na montmorillonita estão presentes nas galerias e $20 \%$ se encontram nas superfícies laterais (Rodríguez e Pinzón, 2001; Leite et. al., 2008; Kozak e Domka, 2004).

$\mathrm{O}$ aquecimento da vermiculita entre as faixas de $800-1000{ }^{\circ} \mathrm{C}$ provoca o afastamento das lamelas na direção axial, fenômeno denominado esfoliação ou expansão, fato ligado a vaporização das moléculas de água contidas entre as camadas (Ugarte et al., 2005). O processo de expansão confere a vermiculita propriedades tais como: aumento do volume (em até 20 vezes), diminuição da densidade, área superficial específica elevada e maior capacidade de troca catiônica (Hora et al., 2009).

As argilas organofílicas são hidrofóbicas, diferentemente das sódicas que são hidrofílicas. Esta característica de serem hidrofóbicas confere a elas inchamento e dispersão em compostos orgânicos como, por exemplo, os derivados de petróleo (Van DOREN, 1987). 
Tentativas de se utilizar a vermiculita, puramente expandida, no tratamento de águas contaminadas com óleos ou no combate a vazamentos de petróleo e seus derivados demonstraram que, apesar das suas altas porosidade e superfície específica, a vermiculita expandida possui baixa capacidade de adsorção de compostos orgânicos, havendo a necessidade da sua hidrofobização (MARTINS, 1992).

Este trabalho tem como objetivo o tratamento de emulsões óleo/água utilizando a vermiculita expandida organofílica e hidrofobizada, avaliando a capacidade de remoção de óleo em emulsões sintéticas.

\section{METODOLOGIA}

\subsection{Expansão da vermiculita in natura}

Inicialmente, mediu-se o peso e o volume de certa quantidade de vermiculita de tamanho uniforme (peneira Tyler de 200 mesh). Em seguida, colocou-se o material em cadinhos, levandoos ao forno mufla durante 15 min na temperatura de $800{ }^{\circ} \mathrm{C}$, com o objetivo de eliminar a água adsorvida na vermiculita nas condições ambientais. Utilizando uma proveta graduada mediu-se o grau de expansão (GE), através da razão entre o volume da vermiculita expandida e in natura. De acordo com a Equação 1 foi calculado o GE:

$$
G E=\frac{V_{\text {exp }}}{V_{\text {in }}}
$$

\subsection{Organofilização da vermiculita expandida}

Inicialmente prepararam-se dispersões contendo $800 \mathrm{~mL}$ de água destilada e $20 \mathrm{~g}$ de argila. A argila foi adicionada aos poucos, sob agitação mecânica e aquecimento a $80^{\circ} \mathrm{C}$ por $25 \mathrm{~min}$. Em seguida foi preparada uma solução aquosa do sal quaternário de amônio (Brometo de Cetiltrimetilamônio) na proporção de $100 \%$ da capacidade de troca catiônica (CTC), adicionando à mistura e mantendo sob agitação por 30 min. Após esse período os recipientes foram fechados e mantidos a temperatura ambiente por 24 horas. Os materiais foram lavados, filtrados com água destilada e, secos em estufa a $80{ }^{\circ} \mathrm{C}$ por 24 horas. O material seco foi desagregado e peneirado em peneira Tyler de 200 mesh.

\subsection{Hidrofobização da vermiculita expandida}

O hidrofobizante utilizado neste trabalho foi a cera de carnaúba líquida. Inicialmente pesou-se cerca de $10 \mathrm{~g}$ de vermiculita expandida e a colocou em um erlenmeyer. Aqueceu-se o sistema até $200{ }^{\circ} \mathrm{C} \mathrm{em}$ uma manta aquecedora isolada termicamente com papel alumínio para evitar perda de calor. Em seguida, adicionou-se $10 \%$ em peso da cera de carnaúba, agitando com 
um bastão de vidro para homogeneizar a mistura durante 2 min. Deixou-se o sistema esfriar a temperatura ambiente e depois passou o material em peneira Tyler de 200 mesh.

\subsection{Preparação das emulsões óleo/água}

Para a obtenção das emulsões utilizou-se o óleo lubrificante mineral da PETROBRAS. Após a realização de cálculos obteve-se as concentrações iniciais de óleo em solução, sendo a concentração inicial uma das variáveis independentes para a realização do planejamento fatorial com pontos centrais. Foram preparadas amostras de $250 \mathrm{~mL}$ de água e sob agitação foi adicionado o cloreto de sódio $(\mathrm{NaCl})$ na concentração de 5000 ppm para simular a salinidade da água do mar. As amostras foram agitadas à $17000 \mathrm{rpm}$ por 20 minutos para garantir a completa formação da emulsão água e óleo. As amostras foram acidificadas até um $\mathrm{pH}$ de aproximadamente 2 para evitar a aderência de gotículas de óleo na parede do recipiente e coagulação da mesma. A Tabela 1 apresenta a matriz das variáveis de entrada utilizadas no Planejamento fatorial, suas codificações e os níveis reais para cada variável do sistema de adsorção em banho finito, para o óleo sobre a vermiculita organofílica e hidrofobizada.

Tabela 1 - Matriz dos ensaios, os níveis reais e codificados das variáveis do Planejamento fatorial $2^{2}$ com três pontos centrais

\begin{tabular}{|c|c|c|c|c|c|c|}
\hline \multirow[t]{2}{*}{ Experimentos } & \multicolumn{2}{|c|}{ Fatores } & Níveis & \multicolumn{2}{|c|}{ Concentração (ppm) } & \multirow{2}{*}{$\begin{array}{l}\text { Tempo } \\
\text { (horas) }\end{array}$} \\
\hline & Concentração & Tempo & & Organofílica & Hidrofobizada & \\
\hline 1 & - & - & $(-1)$ & 108,67 & 108,67 & 1 \\
\hline 2 & + & - & $(+1)$ & 187,00 & 187,00 & 3 \\
\hline 3 & - & + & $(-1)$ & 108,67 & 108,67 & 1 \\
\hline 4 & + & + & $(+1)$ & 187,00 & 187,00 & 3 \\
\hline 5 & 0 & 0 & 0 & 117,67 & 151,00 & 2 \\
\hline 6 & 0 & 0 & 0 & 117,67 & 151,00 & 2 \\
\hline 7 & 0 & 0 & 0 & 117,67 & 151,00 & 2 \\
\hline
\end{tabular}

\subsection{Realização dos Ensaios de Banho Finito}

Os ensaios foram realizados seguindo-se a matriz de ensaios. Pesou-se $0,5 \mathrm{~g}$ de vermiculita e colocou-a em contato com $50 \mathrm{~mL}$ das emulsões com concentrações iniciais definidas na Tabela 1. O conjunto (emulsão óleo/água + vermiculita organofílica e hidrofóbica) foi mantido sob agitação mecânica média em uma mesa agitadora durante os tempos de 1, 2 e 3 horas de forma a garantir o equilíbrio do sistema.

Percentual de remoção (\%Rem) e capacidade de remoção (qeq): Os ensaios realizados através do HORIBA OCMA-350 foram utilizados para a determinação do teor de óleo presente na fase líquida das soluções preparadas e submetidas aos respectivos experimentos. Foi realizada a análise quantitativa sem a geração das curvas de espectrofotometria de infravermelho, devido à ausência do monitor acoplado ao equipamento. A porcentagem de remoção (\%Rem) e a capacidade de remoção (qeq) foram obtidas através das Equações 2 e 3, respectivamente. 


$$
\begin{aligned}
& \% \operatorname{Re} m=\left(\frac{C_{0}-C}{C_{0}}\right) \cdot 100 \\
& q_{e q}=\frac{V}{m}\left(C_{0}-C_{e q}\right)
\end{aligned}
$$

\section{RESULTADOS E DISCUSSÃO}

\subsection{Grau de expansão (GE)}

O resultado do grau de expansão da vermiculita in natura encontra-se na Tabela 2.

Tabela 2 - Resultados do grau de expansão

\begin{tabular}{cccccc}
\hline Temperatura $\left({ }^{\circ} \mathrm{C}\right)$ & $\mathrm{M}_{\text {in }}(\mathrm{g})$ & $\mathrm{M}_{\exp }(\mathrm{g})$ & $\mathrm{V}_{\text {in }}(\mathrm{mL})$ & $\mathrm{V}_{\exp }(\mathrm{mL})$ & $\mathrm{GE}$ \\
\hline 800 & 25,6760 & 23,3632 & 37,0 & 42,0 & $\mathbf{1 , 1 3 5 1}$ \\
\hline
\end{tabular}

De acordo com a Tabela 2 observou-se o aumento do volume da vermiculita com a diminuição da massa devido à evaporação de água. Valores de GE acima de 1,0 são considerados bons resultados de expansão (França e Luz, 2002). A expansão é uma técnica simples e bastante viável, pois o argilomineral adquire maiores capacidades para agregar na sua estrutura moléculas volumosas.

\subsection{Micrografia Eletrônica de Varredura (MEV)}

Na Figura 1 estão apresentadas as Micrografias Eletrônicas de Varredura (MEV) da vermiculita in natura, expandida, organofílica e hidrofobizada, respectivamente.

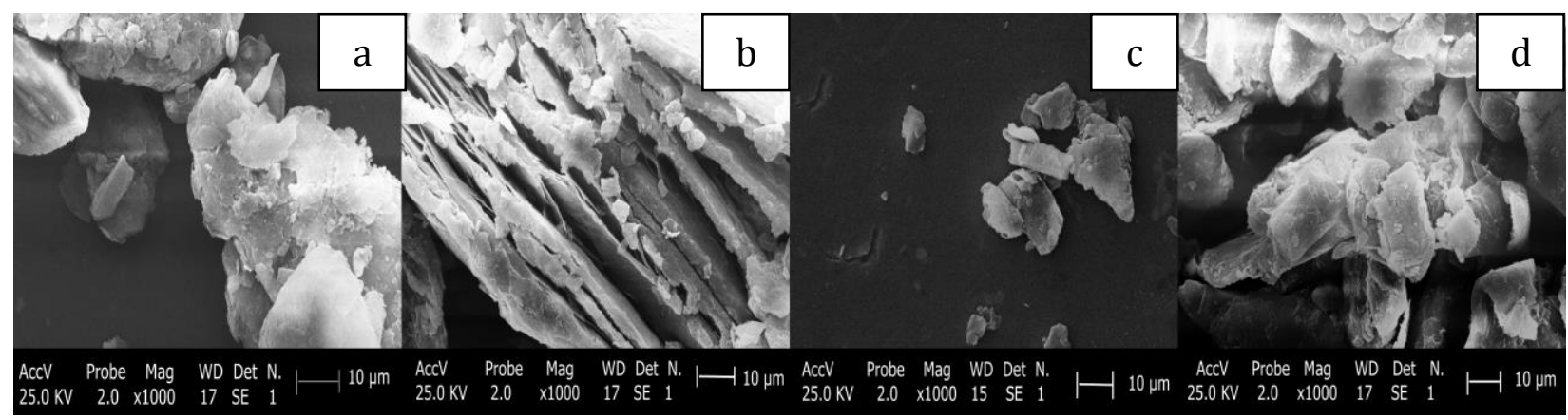

Figura 1- a) vermiculita in natura, b) vermiculita expandida, c) vermiculita organofílica e d) vermiculita hidrofobizada 
Por meio de observações da micrografia da Figura 1a, observou-se uma estrutura compactada e escamosa, formada por aglomerados e pequenos espaçamentos, característica da argila vermiculita no estado natural. Na Figura $1 \mathrm{~b}$ observou-se uma estrutura escamosa e menos compactada, com folhas bem delaminadas e aumento dos espaçamentos interlamelares do material, característica da argila expandida. Nas Figuras 1c e 1d verificou-se aglomerados mais consistentes e escamosos, que pode ser atribuído ao efeito do sal orgânico e da cera de carnaúba sobre a mesma, promovendo a aglomeração das partículas e preenchimento dos espaços vazios.

\subsection{Difratometria de Raios X (DRX)}

Nas Figuras 2 e 3 estão apresentadas as curvas de Difração de Raios X para a vermiculita in natura, expandida, organofílica e hidrofobizada.
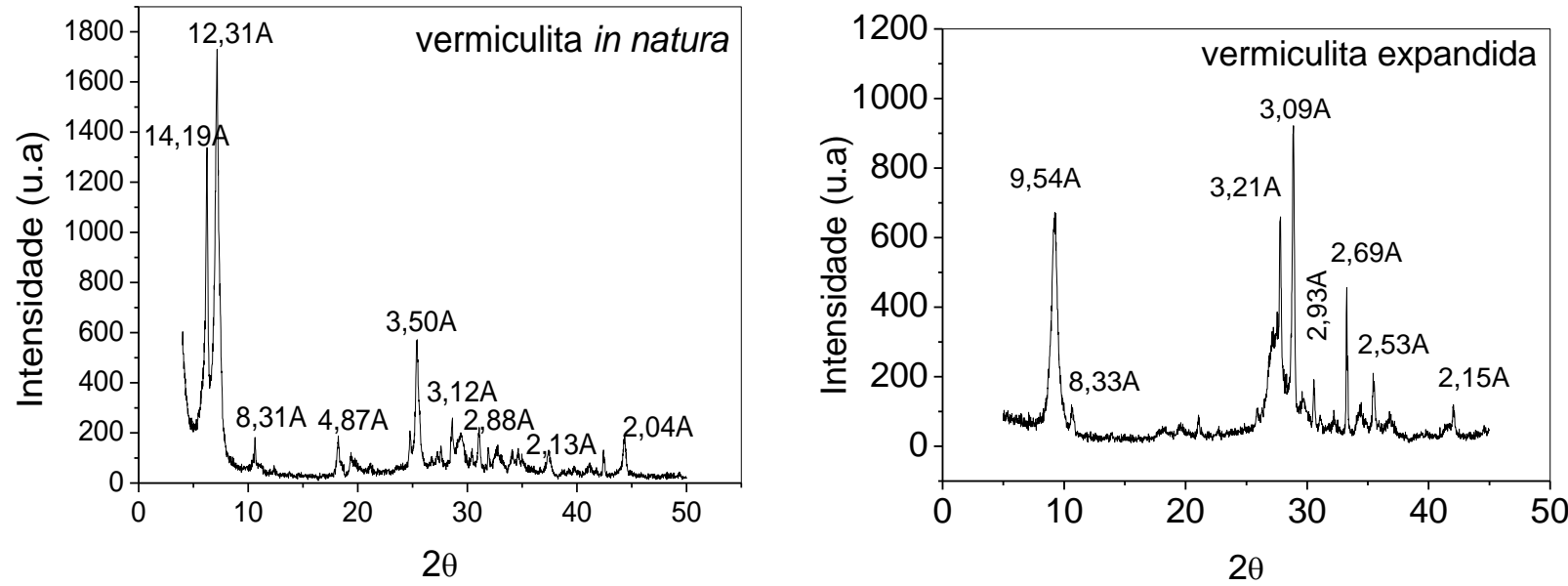

Figura 2 - curvas de Difração de Raios X para as vermiculitas in natura e, expandida.

Observou-se o pico característico da vermiculita com um espaçamento de 14,19 e 9,54 A. Quando aquecida a uma temperatura maior que $800{ }^{\circ} \mathrm{C}$, o pico característico da vermiculita apresentou uma redução na distância interplanar, sendo comprovada na Figura 2 

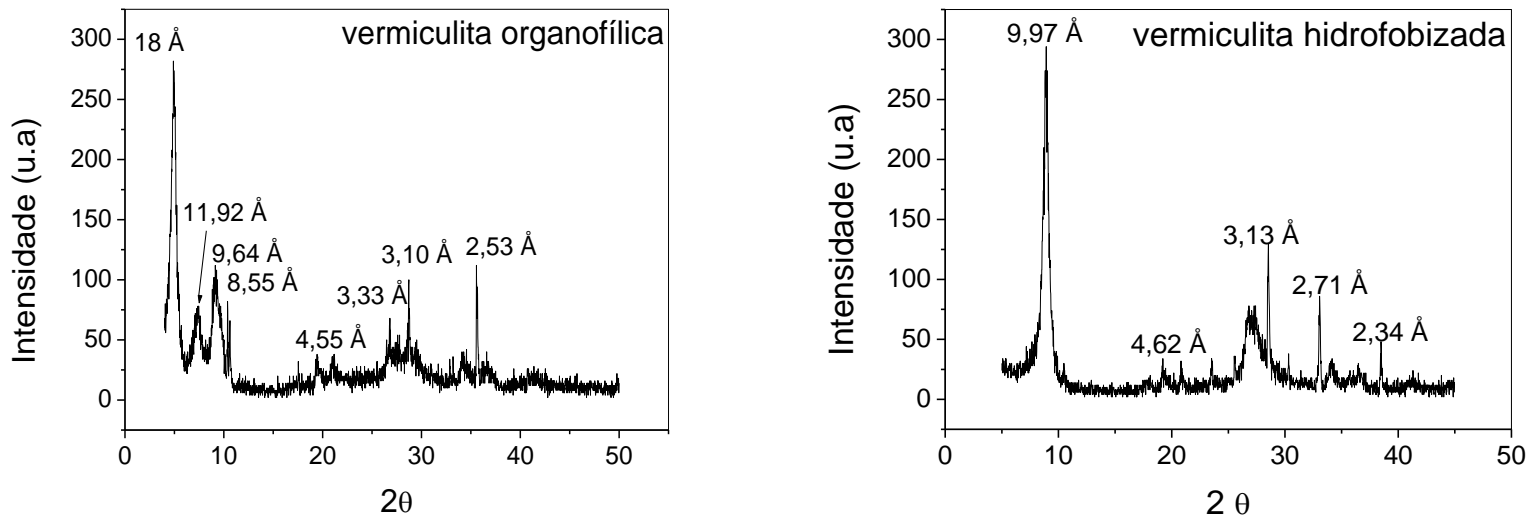

Figura 3 - curvas de Difração de Raios X para as vermiculitas organofílica e, hidrofobizada.

Observou-se na Figura 3 o pico com espaçamentos de $18 \AA$ e 9,97 $\AA$, característicos da vermiculita. Nos processos de organofilização e hidrofobização ocorreu o aumento dessa distância interplanar devido à intercalação do material orgânico entre as camadas interlamelares da vermiculita. Os demais picos são característicos de outros argilominerais.

\subsection{Análises de concentração de óleo através das emulsões óleo/água utilizando o HORIBA OCMA-350}

Os resultados obtidos para a porcentagem e a capacidade de remoção estão apresentados na Tabela 3.

Tabela 3- Porcentagem e a capacidade de remoção das vermiculitas organofílica e hidrofobizada.

\begin{tabular}{ccccccccccc}
\hline & \multicolumn{1}{c}{ Organofílica } & \multicolumn{4}{c}{ Hidrofobizada } \\
\hline E & C.t & T & C.r & C.f & $\%$ & q.e.q & C.r & C.f & $\%$ & q.e.q \\
& ppm & h & ppm & ppm & & $\mathrm{mg} / \mathrm{g}$ & $\mathrm{ppm}$ & $\mathrm{ppm}$ & & $\mathrm{mg} / \mathrm{g}$ \\
\hline 1 & 50 & 1 & 108,67 & 11,17 & 89,54 & 4,88 & 108,67 & 55,63 & 48,80 & 2,65 \\
2 & 100 & 1 & 187,00 & 17,20 & $\mathbf{9 0 , 8 0}$ & $\mathbf{1 6 , 9 8}$ & 187,00 & 29,53 & $\mathbf{8 4 , 2 1}$ & $\mathbf{1 5 , 7 5}$ \\
3 & 50 & 3 & 108,67 & 13,07 & 87,98 & 4,78 & 108,67 & 53,20 & 51,04 & 2,77 \\
4 & 100 & 3 & 187,00 & 19,57 & $\mathbf{8 9 , 7 2}$ & $\mathbf{1 6 , 7 4}$ & 187,00 & 24,50 & $\mathbf{8 6 , 9 0}$ & $\mathbf{1 6 , 2 5}$ \\
5 & 75 & 2 & 117,67 & 13,20 & 88,78 & 7,84 & 151,00 & 31,00 & 79,47 & 9,00 \\
6 & 75 & 2 & 117,67 & 8,20 & 93,03 & 8,21 & 151,00 & 50,27 & 66,71 & 7,56 \\
7 & 75 & 2 & 117,67 & 7,43 & 93,68 & 8,27 & 151,00 & 50,30 & 66,69 & 7,55 \\
\hline
\end{tabular}

Legenda: $\mathrm{E}=$ ensaios da emulsão + vermiculita, C.t = Concentração teórica, $\mathrm{T}=$ Tempo de agitação (horas), C.r = concentração real, C.f = concentração final, $\%=$ porcentagem de remoção, q.e.q = capacidade de remoção. 
Através da Tabela 3 observou-se que os melhores resultados de percentual de remoção (\% Rem) da vermiculita organofílica na emulsão foram os ensaios 2 e 4 com 90,80\% e 89,72\%, respectivamente. Para a vermiculita hidrofobizada os ensaios 2 e 4 tiveram a melhor \% Rem, com $84,21 \%$ e $86,90 \%$, respectivamente. Para a capacidade de remoção ( $\mathrm{q}_{\mathrm{eq}}$ ), os melhores resultados foram para os ensaios $2(16,98)$ e $4(16,74)$ respectivamente, da vermiculita organofílica e, para a vermiculita hidrofobizada os melhores foram para os mesmos ensaios com 15,75 e 16,25 respectivamente, demonstrando maior adsorção de óleo por grama de adsorvente.

\subsection{Análise do planejamento fatorial}

A Tabela 4 apresenta a saída do Minitab 16.0 para a ANOVA, referente à porcentagem de remoção de óleo, usada para determinar ao nível de $5 \%$ de significância quais fatores são significativos.

Tabela 4 - Análise de variância (ANOVA) para porcentagem de remoção para a vermiculita organofílica e hidrofobizada

\begin{tabular}{lcrllrrl}
\hline & & \multicolumn{3}{c}{ Vermiculita organofílica } & \multicolumn{3}{c}{ Vermiculita hidrofóbica } \\
\cline { 2 - 8 } Fonte de Variação G. L. & S. Q. & Q. M. A. p-valor & S. Q. & Q. M. A. & p-valor \\
\hline Efeito Principal & 2 & 3,9924 & 1,9962 & 0,780 & 1275,52 & 637,76 & 0,079 \\
Concentração & 1 & 1,7424 & 1,7424 & 0,669 & 1269,45 & 1269,45 & $\mathbf{0 , 0 4 0}$ \\
Tempo & 1 & 2,2500 & 2,2500 & 0,630 & 6,08 & 6,08 & 0,770 \\
C*T & 1 & 0,0576 & 0,0576 & 0,936 & 0,05 & 0,05 & 0,978 \\
Curvatura & 1 & 9,2270 & 9,2270 & 0,372 & 17,76 & 17,76 & 0,625 \\
Erro Residual & 2 & 14,1650 & 7,0825 & - & 108,72 & 54,36 & - \\
Puro Erro & 2 & 14,1650 & 7,0825 & - & 108,72 & 54,36 & - \\
Total & 6 & 27,4420 & - & - & 1402,06 & - & - \\
\hline \multicolumn{3}{c}{} & - & \multicolumn{3}{c}{$\mathrm{R}^{2}=48,38 \%$} & \multicolumn{3}{c}{$\mathrm{R}^{2}=92,25 \%$} & \\
\hline
\end{tabular}

Legenda: G.L = grau de liberdade, S.Q = soma quadrática, Q.M.A = quadrado médio ajustado, $\mathrm{R}^{2}=$ coeficiente de determinação

A ANOVA apresentou o p-valor igual a 0,780 para a vermiculita organofílica e 0,079 para a vermiculita hidrofóbica, os quais são maiores que 0,05. Pode-se afirmar, então que o fator concentração para a vermiculita organofílica não foi significativo e para a vermiculita hidrofóbica influenciou na resposta e, o fator tempo, das duas vermiculitas, não influenciou na variável resposta (Conversão). O p-valor $(0,936)(0,978)$, para a interação entre os fatores também foi maior que $0,05, \operatorname{logo}$ a interação entre os fatores não influenciou na conversão. 


\section{CONCLUSÕES}

Nos difratogramas confirmou-se o aumento da intensidade do pico característico da vermiculita para o material organofílico e hidrofobizado. As vermiculitas organofílica e hidrofobizada, apresentaram altos percentuais de remoção para as emulsões com concentração de 100 ppm tratadas por 1 e 3 horas de agitação. Os fatores tempo e a interação entre os fatores concentração e tempo não foram significativos ao nível de $5 \%$ de significância. $O$ fator concentração foi significativo para a vermiculita hidrofobizada.

\section{AGRADECIMENTOS}

Os autores deste trabalho agradecem ao CAPES/PET/DEQ/UFCG.

\section{REFERÊNCIAS}

FRANÇA, S. C. A.; LUZ, A. B. Utilização da vermiculita como adsorvente de compostos orgânicos poluentes da indústria do petróleo. In: XIX Encontro Nacional de Tratamento de Minérios e Metalurgia Extrativa. p. 547-553, Recife. 2002.

HORA P. H. A,; TAVARES, M. R. S.; JÚNIOR, U. G. S. Tratamento de águas residuárias através de argila modificada. Instituto Federal de Educação, Ciência e Tecnologia da Paraíba IFPB, 2009.

KOZAK, M.; DOMKA, L.; Adsorption of the quaternary ammonium salts on montimorillonite. J.Physics and Chemistry of Solids, 65, 441-445, 2004.

LEITE, I. F.; RAPOSO, C. M. O., SILVA, S. M. Caracterização estrutural de argilas bentoníticas nacional e importada: antes e após o processo de organofilização para utilização como nanocargas. Cerâmica, V.54, p.303-308, 2008.

MARTINS, J.M., Processo Aperfeiçoado de Hidrofobização de Vermiculita Expandida, Instituto Nacional da Propriedade Industrial, PI 9004025-A, 25/02/92, 1992.

RODRÍGUEZ-SARMIENTO, D. C.; PINZÓN-BELLO, J. A.; Adsorption of sodium dedecylbenzene sulfonate on organophilic bentonites. Applied Clay Science, 18, 173-181, 2001.

VAN OPHEN, H. An introduction to Clay Colloid Chemistry, $2^{\text {nd }}$ ed., John Wiley, New York ,1977.

UGARTE, J.F.O; SAMPAIO, J.A.; FRANÇA, S.C.A. Rochas e Minerais Industriais. Ouro Preto: CETEM. 2005. 